\title{
Effect, Problems and Countermeasures of "Internet+" in Animal
}

\section{Husbandry in China}

\author{
ZHANG Fu-cheng $^{1, a}$, YANG Chun ${ }^{2, b}$, MENG Zhi-xing ${ }^{1, c}$ \\ ${ }^{1}$ College of Economics and Management, Shanxi Agricultural University, Taigu Shanxi, P.R. China \\ ${ }^{2}$ Institute of Agricultural Economics and Development, Chinese Academic of Agricultural Sciences, \\ Beijing, P.R. China

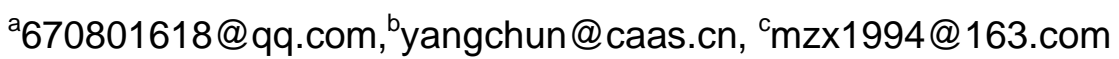

Keywords: Internet+; animal husbandry; modern technology system; E-commerce

Abstract: "Internet+" provides new ideas for the development of traditional industry will bring profound influence on industrial production and operation. The "Internet+ animal husbandry" is to integrate new internet technologies in each production links of animal husbandry and finally realize "intelligent" animal husbandry. The paper analyzes prominent problems suffered by "Internet+ animal husbandry" at present and proposes relevant suggestions on the basis of describing the effect of "Internet+ animal husbandry" in China.

Suggestions for "Internet+" Actions (hereinafter referred to as Suggestions) was passed on executive meeting of the State Council in June, 2015, and since then "Internet+" turns into a national strategy. The Suggestions provides new ideas for the development of traditional industry, brings profound influence on industrial production and operation thoughts and will certainly lead to new industrial revolution. The animal husbandry, as a traditional industry, has achieved some achievements in recent years, but it also takes on many problems during development, such as industrial decentralization and low informatization degree, which causes excessive transaction cost and insufficient development potential. In current economic transition period, the animal husbandry must seize the "Internet+" opportunity, participate in "Internet+" actively, analyze the mechanism and way for modern animal husbandry transition deeply and raise the efficiency of each link based on big data from computer and internet, cloud computing and other technologies.

The "Internet+ animal husbandry" is to apply new internet technologies (information \& communication technology, cloud computing, big data and internet of things etc.) to traditional animal husbandry, including feed production, animal feeding, slaughter, processing, storage, transport, sales and quality safety monitoring of livestock product and all-round supervision to the whole industrial chain, in order to promote the production efficiency, product quality, culture benefit and management efficiency and realize true "smart animal husbandry". The "Internet+ animal husbandry" is to integrate new internet technologies in each production links of animal husbandry and finally realize "intelligent" animal husbandry.

\section{Effect of Developing “Internet+ Animal Husbandry"}

\section{Accelerating information spreading speed and promoting the generalization of innovative technology}

Traditional information spreading of animal husbandry depends on newspaper, advertisement and other traditional media disadvantage is long generalization time, high cost and low efficiency. However, the rising of internet technology changes those traditional spreading ways at root. The 
characteristics of "Internet+", including lower entry barrier and fast information updating speed, bring convenience to information exchange between producer and seller and relieve the contradiction of information asymmetry to a large extent.

Except for accelerating information exchange speed, the internet could also facilitate the generalization, popularization and efficiency of innovative technology. With supports from internet, industrial technical backbones could exchange their experiences on new technology and new process and share what they have learned during feeding timely. Such powerful radiation capacity has a positive effect on innovation and generalization of husbandry technology. Such innovative development mode could provide powerful technical support for the transformation and upgrading of animal husbandry.

\section{Changing circulation mode of livestock products and enhancing circulation efficiency}

As to traditional livestock products, the production \& marketing chain has a complicated composition structure, excessive intermediate circulation links, low circulation efficiency and serious loss. The "Internet+ animal husbandry" could enable producers and consumers to share information fully, shorten production $\&$ marketing chain, enhance circulation efficiency and reduce intermediate costs. More raising households and cooperatives depart from traditional market to sell their products on internet directly, which greatly improves bargaining power and expands market area. Due to the disclosure, transparency and fast spreading of information of mobile social network, consumers could get more information fast, break isolate limit of information receiving, synchronize information with producers, turn to active participation from passive consumption, take up leading role in production \& marketing pattern and achieve E-commercial purchasing mode of "internet order".

\section{Facilitating the building of technical service system of modern animal husbandry}

As China has a vast territory and local animal husbandries have their own characteristics, plenty of husbandry service technicians have to conduct technical guidance and generalization according to local conditions. As to raising households, the information is inaccessible, and they could not master the market information or epidemic situation in time. Based on the support from internet information technology, it's able to accelerate the development of traditional technical service system of animal husbandry to informatization and digitization, make services much convenient and effective and realize the modernization, informatization and practicality of technical service system based on remote network service system. Besides, with the remote network service system, it's able to ease the dilemma of technical personnel shortage in a short time, help governments and enterprises to master market trends so as to make market forecasting and adjust production structure in time and enable more practitioners to master more advanced technologies and enhance productivity.

\section{Prominent Problems Faced}

\section{Late internet utilization in animal husbandry and no mature experiences}

Animal husbandry, as an important part of agricultural sector, offers necessary livestock products to human beings. But, the management mode of current animal husbandry is extensive management with laggard production capacity. Even the reformed mode of scale raising and intensive management fails to consider the important influence of internet on production and management. The selects for consumers on livestock products are few. Because of limited market coverage, livestock enterprises access to markets still by quantitative superiority and low-price strategy and neglect potential values that shall be brought by brand effect.

Traditional animal husbandry wants development with the help of internet economy. Although 
there are successful cases, there are many limits still, such as low information application level, disperse information receiver and substandard technical condition. Livestock products are different from industrial products that could realize standardized production via a series of technical indexes. Livestock products depend on the natural production of animals and plants and undertake certain natural risks. Moreover, there are problems in continuous product supply. Therefore, there are many problems on internet application in animal husbandry to be solved and feasible development experiences have to be accumulated as well.

\section{Complicated information platform and reference value remaining to be improved}

In internet era, the information spreading and updating speed improves greatly, and internet has become the main way for information spreading of animal husbandry. Therefore, many information publishing platforms emerge, and they provide timely and comprehensive raw material quotation, product market quotation and epidemic situation of diseases and have become an important channel for husbandry practitioners to obtain production information. However, the internet information is numerous and complicated, and it's hard to distinguish whether it's true or false. As authoritative information publishing platform is scarce, it's much difficult for practitioners to obtain and utilize information. This information could not be used to guide production and operation completely, and as animal husbandry has a high requirement on information timeliness in especial, only timely and accurate information could be used to produce values.

The particularity of livestock products making them difficult to be sold on E-commercial platform

Different from common products, livestock products have strict requirements on transport preservation. When consumers purchase livestock products on E-commercial platform, livestock products will be sent to consumers after order receiving, packaging, shipment and transportation, and each link needs time. However, livestock products are easy to go bad, current logistic service system is imperfect, and the service quality needs to be improved, all of which cause great risks in product circulation link.

Meanwhile, as for traditional purchasing mode, consumers could see the products bought actually. As to fresh and alive livestock products, consumers hope to check product quality more. The products on E-commercial platform are virtual introduction only and could not offer direct sensory feelings. With regard to theses special products with transportation risk, the acceptance level is still low.

\section{Countermeasures and Suggestions}

\section{Perfecting infrastructures for "Internet+ animal husbandry" and training informationalized talents}

Although some achievements have been realized at present, the animal husbandry still has to explore the development way, make systematic planning with internet thought combining with industrial characteristics, formulate policies for smart animal husbandry to guide development, build and perfect technical service system for modern animal husbandry, coordinate with relevant departments to further improve internet infrastructure, including fiber broadband and mobile network etc., adopt practical and effective manner to establish database, found national data sharing platform, update and manage the data in time.

In recent years, influenced by market risk and epidemic prevention and control, the price of livestock product fluctuates greatly, which affects the access of high-quality talents. Therefore, talents and technologies shall be emphasized when perfecting hardware. Two aspects shall be emphasized on talent cultivation; the first one is to improve informationalized education to 
agricultural talents and enhance their informatization application level; and the second one is to bring in a group of talents that know about agricultural knowledge and master information technology skillfully, guide them in actual work and develop them into the main force for accelerating agricultural informationalized development.

\section{Building authoritative information service platform}

The information platform is very significant for developing "Internet+ animal husbandry". A modern information service platform shall fully mobilize various technology extension organizations, husbandry enterprises and scientific research institutions to conduct information collection and arrangement well, strengthen the application of big data, cloud computing, mobile network, internet of things and other advanced and applicable technologies in husbandry production and management, advance the informatization level and improve the authority of information platform.

Based on big data analysis technology, the animal husbandry shall effectively develop and utilize information database, boost scientific development, strengthen market forecasting and judgment, update production technology in real time, put forward ecological pre-warning and quality safety pre-warning, prevent and control disease effectively and boost production modernization with informatization.

Facilitating the establishment of E-commercial platform and improving logistic system

Along with the development of internet technology, E-commerce becomes a crucial link of animal husbandry transformation and upgrading. Such $\mathrm{O} 2 \mathrm{O}$ mode is internal needs of modern consumers for high-quality service, could help consumers to reduce purchasing cost and is able to promote the influence of livestock products in demand aspect. In addition, E-commerce could satisfy enterprise's needs for market information and enable enterprises to optimize structures based on obtained market information and broaden sales market. Therefore, it's necessary to build the marketing network covering the whole country or world for livestock products so as to realize online transaction. Meanwhile, it's necessary to cultivate a batch of express and logistic enterprises with good reputation, high-efficiency management and considerate service, integrate existing warehousing and transport resources and build E-commercial logistic and warehousing base with high systematization and informatization level so as to shorten the time from breeding to utilization of livestock products and guarantee the freshness and safety of products.

\section{Acknowledgements}

This work was financially supported by National Natural Science Funds of China (71503251), The Agricultural Science and Technology Innovation Program (ASTIP-IAED-2015-01), China forage and grass research system(CARS-35-22).

Corresponding Author: YANG Chun.

\section{References}

[1]Cao Dongqing and Cao Zhongzan. The Development of Animal Husbandry Shall Rely on "Internet+". Chinese Abstracts of Animal Husbandry and Veterinary Medicine, 2015, 31 (10): 4-5. [2]Zhao Lichang. Internet Economy and China Industrial Transformation and Updating. Contemporary Economic Management, 2015. 12: 54-59, 45.

[3]Xie Jie, Li Peng and Bao Rongcheng. Mechanism and Way Selection for Transformation and Updating of Modern Animal Husbandry-Analysis Based on "Internet+" Animal Husbandry Mode, 2016, 52 (10): 43-48. 